\title{
Pedagogia universitária e formadores de professores de Educação Física: o que expressam as produções científicas?
}

\author{
Higher Education Pedagogy and Physical Education teachers' educators: what the scientific \\ productions express?
}

Pedagogía universitaria y formadores de docentes de Educación Física: ¿lo que expresan las producciones científicas?

Adriana Claudia Martins ${ }^{\mathrm{I}}$, Daniela de Moura Clates ${ }^{\mathrm{II}}$, Heloisa Elesbão ${ }^{\mathrm{II}}$, Maria Cecília da Silva Camargo ${ }^{\mathrm{VI}}$

\begin{abstract}
Resumo
A investigação é desenvolvida no Programa de Pós-graduação em Educação Física da Universidade Federal de Santa Maria/RS e consiste em um levantamento do tipo estado da arte, estudo direcionado aos princípios da pesquisa bibliográfica. A proposta está estruturada a partir da investigação de produções científicas publicadas nos principais bancos de teses/dissertações e artigos científicos que abordam a formação de professores formadores de Educação Física e a pedagogia universitária, no período entre 2009-2019. Os resultados indicam a incipiência de estudos nessa temática e área, sinalizando a importância de mais pesquisas. Identifica-se, entretanto, que a autoformação e os conhecimentos subjacentes à docência universitária estão presentes nas produções analisadas.
\end{abstract}

Palavras-chave: Educação Superior; Aprendizagem; Ensino

\begin{abstract}
The research is developed in Physical Education Postgraduate Program of Santa Maria Federal University/RS, Brazil, and it consists of a study called state of art, directed to the principles of bibliographic research. The proposal is structured from the investigation of scientific productions published in the main databases of theses /dissertations and scientific articles that report the educators formative process of Physical Education and the Higher Education Pedagogy, from 2009 and 2019.The results signpost the incipience of studies on this theme and area, signaling the importance of further researches. It is identified, however, that self-training and knowledge underlying university teaching are present in the analyzed productions.
\end{abstract}

Keywords: Higher Education; Learning; Teaching

\footnotetext{
I Universidade Federal de Santa Maria - UFSM - Santa Maria, RS, Brasil - endereço: Av. Roraima, 1000. Prédio 51. Sala 2051 - e-mail: teacheradrianacm@hotmail.com

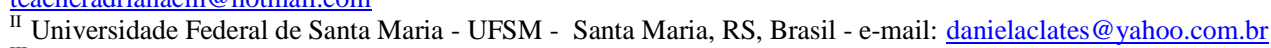

${ }^{\text {III }}$ Universidade Federal de Santa Maria - UFSM - Santa Maria, RS, Brasil - e-mail: heloisaelesbao@bol.com.br

${ }^{\text {VI Universidade Federal de Santa Maria - UFSM - Santa Maria, RS, Brasil - e-mail: mceciliacg6@ hotmail.com }}$
} 


\section{Resumen}

La investigación se desarrolla en el Programa de Postgrado en Educación Física de la Universidad Federal de Santa María / RS y consiste en un estudio llamado estado del arte, dirigido a los principios de la investigación bibliográfica. La propuesta se estructura a partir de la investigación de producciones científicas publicadas en los principales bancos de tesis / disertaciones y artículos científicos que abordan la formación de docentes de Educación Física y pedagogía universitaria, en el período 2009-2019. Los resultados indican la insipiencia de los estudios sobre este tema y área, lo que indica la importancia de más investigaciones. Sin embargo, se identifica que la autoformación y el conocimiento subyacente a la enseñanza universitaria están presentes en las producciones analizadas.

Palabras clave: Educación superior; Aprendizaje; Enseñanza

\section{Introdução}

A temática da pedagogia universitária e da formação de formadores de professores tem sido divulgada por autores em diferentes países: Schön (1995); Zeichner (1993); Nóvoa (1995); Marcelo Garcia (2009); Pérez-Gómez (1992). No Brasil, contamos com os estudos realizados na área da Educação, entre esses: Mizukami (1996); Morosini (2006); Isaia (2006); Cunha (2000); Cunha e Broilo (2008); Isaia e Bolzan (2007); Isaia, Bolzan e Maciel (2009); Martins (2018). Na especificidade da Educação Física temos como exemplos os estudos de Gerez e Bracht (2019), de Figueiredo (2004) e de Figueiredo et al (2008). Para ampliar as discussões, as questões que nos movem buscam responder: o que indicam as produções científicas, dissertações, teses e os artigos em revistas da área da área da Educação Física? Esses estudos investigam a pedagogia universitária ${ }^{l}$ e a formação de formadores de professores de Educação Física?

A investigação teve como objetivo realizar um mapeamento das produções científicas na área da Educação Física, buscando identificar se há estudos na especificidade desse campo que contemplam a pedagogia universitária e a formação dos formadores de professores. O estudo é desenvolvido no Programa de Pós-graduação em Educação Física da Universidade Federal de Santa Maria/RS, na linha de pesquisa Estudos socioculturais e pedagógicos da Educação Física e é uma pesquisa realizada por integrantes do grupo de pesquisa PÁTIO (Estudos qualitativos sobre formação de professores e prática pedagógica em Educação Física).

A docência e a formação de docentes de Cursos de Educação Física adquirem fundamental importância ao identificarmos a necessidade de transformar a pedagogia universitária. A aproximação das publicações científicas que precedem e que contextualizam o campo dos saberes a serem estudados são essenciais, porque

${ }^{1}$ De acordo com Morosini (2006, p. 57), a Pedagogia universitária tem como "objeto de estudo o ensino, a aprendizagem e a avaliação na universidade, preocupa-se com a formação docente para o exercício pedagógico profissional”. 
os conhecimentos construídos no campo teórico-prático agregam e indicam caminhos a serem ainda pesquisados.

Para chegar à proposta de uma pedagogia universitária que faça a ponte entre o mundo da vida e o mundo da cultura (BAKHTIN, 2010), é preciso que o ato docente seja capaz de relacionar esses dois mundos, estabelecendo relações de sentido e de significado entre o contexto vivido/ prático e a teoria/cultura, de modo que a construção do conhecimento aconteça nesse andar sobre a ponte, cuja travessia é um caminho permeado por saberes e interpretações interligadas e significadas entre o que é vivido e o que é teorizado. O mundo da vida e o mundo da cultura devem se constituir em uma relação corresponsiva, "seja em relação ao seu conteúdo (responsabilidade especial), seja em relação ao seu existir (responsabilidade moral)" (BAKHTIN, 2010, p. 43).

Nesse ínterim, entendemos como importante conhecer como os professores universitários têm organizado suas dinâmicas e propostas pedagógicas. Por isso, a busca por trabalhos publicados pode auxiliar nesse mapeamento e reconhecimento do que já se construiu como paradigma que considera a aprendizagem e os conhecimentos já construídos pelos estudantes como centrais na docência universitária.

No desenho deste texto, após esta introdução, apresentamos a metodologia de busca e, na sequência, mostramos as produções encontradas no mapeamento, situando as ocorrências e discutindo essas produções. Posteriormente, são indicados os resultados e considerações finais, os quais sinalizam e articulam, em termos de pesquisas, no contexto da pedagogia universitária e no campo da Educação Física.

\section{Metodologia de busca e de análise}

Por ser este um estudo com princípios da pesquisa bibliográfica, as buscas foram realizadas a partir de teses e dissertações e de periódicos científicos da área de Educação Física. No cenário de produções científicas foram considerados os elementos relativos à docência e à formação de professores universitários. O acesso às teses e às dissertações deu-se pela Biblioteca Digital de Teses e Dissertações (BDTD) e a busca nos periódicos deu-se pela disponibilidade de leitura gratuita e/ou acesso on-line. Como recorte temporal, foram consideradas as produções científicas entre os anos de 2009 e de2019.

Assim, a investigação foi organizada a partir das palavras de busca, lançadas de modo simultâneo: Pedagogia universitária; docência; Educação Superior; Ensino Superior; aprendizagem; Educação Física. Quando essas foram localizadas no título, ainda que uma delas apenas estivesse presente, 
seguíamos com a leitura das palavras-chave e do resumo do texto publicado. Quando esse caminho não respondia e não nos dava certeza de que a publicação tratava do escopo de busca, então líamos a introdução e a conclusão, ou ainda, o trabalho na íntegra, a fim de nos certificarmos que o texto se articulava ao objeto de pesquisa.

Esse direcionamento de busca por publicações corrobora ao indicar novos paradigmas no contexto da docência de formadores de professores de Educação Física, com outras investigações. A aproximação a estudos que nos precedem, em um dado campo de conhecimento, é efetivo para o desenvolvimento de futuras pesquisas, considerando que é no confronto com outros conhecimentos e publicações que o estudo desconhecido se justifica e a pesquisa se organiza.

\section{Mapeamento em periódicos}

As Revistas pesquisadas foram: Revista Brasileira de Ciências do Esporte (RBCE), Pensar a Prática, Movimento, Motrivivência, Motriz, Revista Brasileira de Educação Física e Esporte (USP) e Revista de Educação Física (UEM)/Journal of Physical Education. Essas publicações estão classificadas entre A2 e B2 na Qualis/Capes (2013-2016). Do total dessas sete (7) revistas consultadas, com publicações ao longo de dez (10) anos, as buscas sofreram adequações em duas (2) dessas revistas: Revista Brasileira de Educação Física e Esporte (USP) e Motriz, pois a sequência de publicações traz interrupções, porque não estão publicadas no site da revista em algumas de suas edições, sendo localizadas apenas em outras plataformas, as quais não fazem parte desta metodologia de pesquisa, considerando-se que são acessos que precisam ser pagos.

A partir das revistas consultadas, encontramos 4.318 trabalhos publicados, sendo que apenas vinte (20) dessas publicações científicas convergem no objetivo de busca desta investigação. Esses trabalhos selecionados, apresentados no Quadro 1, discutem acerca do trabalho docente, das concepções e vivências na Educação Superior, tendo por referência o campo da Educação Física.

Quadro 1 - Publicações científicas nos periódicos da área.

\begin{tabular}{|c|c|c|c|}
\hline Revista & Título & Autor(es)/Ano & Edição \\
\hline \multirow{2}{*}{$\begin{array}{c}\text { Revista } \\
\text { Brasileira de } \\
\text { Ciências do } \\
\text { Esporte } \\
\text { (RBCE) }\end{array}$} & $\begin{array}{c}\text { O papel da formação inicial no processo de } \\
\text { constituição da identidade profissional de professores } \\
\text { de Educação Física }\end{array}$ & Gariglio (2010) & $\begin{array}{l}\text { v. } 32, \\
\text { n. } 2-4\end{array}$ \\
\hline & $\begin{array}{l}\text { Trabalho docente na Educação Superior: reflexões } \\
\text { epistemológicas no campo da Educação Física }\end{array}$ & $\begin{array}{l}\text { Rezer et al. } \\
\quad(2012)\end{array}$ & $\begin{array}{l}\text { v. } 34, \\
\text { n. } 4\end{array}$ \\
\hline Pensar a & $\begin{array}{l}\text { A docência universitária em Educação Física: da } \\
\text { formação à atuação profissional }\end{array}$ & Pires et al. (2018) & $\begin{array}{l}\text { v. } 21, \\
\text { n. } 2\end{array}$ \\
\hline
\end{tabular}




\begin{tabular}{|c|c|c|c|}
\hline Prática & $\begin{array}{l}\text { O trabalho docente no ensino superior em Educação } \\
\text { Física sob a ótica dos pesquisadores brasileiros }\end{array}$ & $\begin{array}{l}\text { Broch et al. } \\
\text { (2019) }\end{array}$ & $\begin{array}{l}\text { v. } 22 \text {, } \\
\text { n. } 5\end{array}$ \\
\hline \multirow{6}{*}{ Movimento } & $\begin{array}{l}\text { Licenciatura em Educação Física: concepções a partir } \\
\text { da vivência experienciada dos professores do ensino } \\
\text { superior em seu percurso formativo }\end{array}$ & $\begin{array}{l}\text { Krüger e Krug } \\
\quad(2009)\end{array}$ & $\begin{array}{l}\text { v. } 15 \text {, } \\
\text { n. } 01\end{array}$ \\
\hline & $\begin{array}{c}\text { Reflexiones didáctico-pedagógicas acerca de la } \\
\text { enseñanza del deporte en el proceso de formación de } \\
\text { profesores de Educación Física }\end{array}$ & Rezer (2010) & $\begin{array}{l}\text { v. } 16, \\
\text { n. } 1\end{array}$ \\
\hline & $\begin{array}{l}\text { O discurso real e o discurso ideal de professores de } \\
\text { Educação Física do Ensino Superior sobre docência }\end{array}$ & $\begin{array}{l}\text { Silva, Andrade e } \\
\text { Zanelli (2010) }\end{array}$ & $\begin{array}{l}\text { v. } 16 \text {, } \\
\text { n. } 3\end{array}$ \\
\hline & A "escrita de si" na formação em Educação Física & $\begin{array}{l}\text { Alves, Carvalho e } \\
\text { Dias (2011) }\end{array}$ & $\begin{array}{l}\text { v. } 17, \\
\text { n. } 2\end{array}$ \\
\hline & $\begin{array}{l}\text { Identidade docente no Ensino Superior de Educação } \\
\text { Física: aspectos epistemológicos e substantivos da } \\
\text { mercantilização educacional }\end{array}$ & $\begin{array}{l}\text { Vieira e Neira } \\
\quad(2016)\end{array}$ & $\begin{array}{l}\text { v. } 22 \text {, } \\
\text { n. } 3\end{array}$ \\
\hline & $\begin{array}{l}\text { A prática reflexiva como possibilidade de construção } \\
\text { de saberes: contribuições para a formação docente na } \\
\text { Educação Física }\end{array}$ & $\begin{array}{l}\text { Muñhoz, Rossi e } \\
\text { Riveros (2017) }\end{array}$ & $\begin{array}{l}\text { v. } 23 \text {, } \\
\text { n. } 2\end{array}$ \\
\hline \multirow{3}{*}{ Motrivivência } & $\begin{array}{c}\text { Um ensaio sobre o método emancipatório de ensino } \\
\text { na Educação Física }\end{array}$ & $\begin{array}{l}\text { Garcia e Pereira } \\
\text { (2019) }\end{array}$ & $\begin{array}{l}\text { v. } 31, \\
\text { n. } 57\end{array}$ \\
\hline & $\begin{array}{l}\text { Formação de professores universitários na pós- } \\
\text { graduação stricto sensu em Educação Física no } \\
\text { Brasil: uma revisão sistemática }\end{array}$ & $\begin{array}{l}\text { Teixeira et al. } \\
\quad(2019)\end{array}$ & $\begin{array}{l}\text { v. } 31, \\
\text { n. } 59\end{array}$ \\
\hline & $\begin{array}{l}\text { As faces da precariedade do trabalho docente e as } \\
\text { estratégias de ação de professores de Educação Física } \\
\text { atuantes no ensino superior privado mercantil }\end{array}$ & $\begin{array}{l}\text { Gerez e Bracht } \\
\quad(2019)\end{array}$ & $\begin{array}{l}\text { v. } 31, \\
\text { n. } 60\end{array}$ \\
\hline \multirow{3}{*}{$\begin{array}{l}\text { Revista de } \\
\text { Educação } \\
\text { Física } \\
\text { (UEM)/ } \\
\text { Journal of } \\
\text { Physical } \\
\text { Education }\end{array}$} & $\begin{array}{c}\text { Práticas pedagógicas como cenário para a construção } \\
\text { do conhecimento pedagógico do conteúdo dos } \\
\text { futuros professores de Educação Física }\end{array}$ & $\begin{array}{l}\text { Marcon, Graça e } \\
\text { Nascimento } \\
(2012) \\
\end{array}$ & $\begin{array}{l}\text { v. } 23 \text {, } \\
\text { n. } 2\end{array}$ \\
\hline & $\begin{array}{l}\text { Formação inicial para a docência: o estágio curricular } \\
\text { supervisionado na visão de seus coordenadores }\end{array}$ & $\begin{array}{c}\text { Biscosini, Flores e } \\
\text { Oliveira (2016) }\end{array}$ & v. 27 \\
\hline & $\begin{array}{l}\text { Os professores de Educação Física e a paixão pela } \\
\text { atividade docente no Ensino Superior }\end{array}$ & $\begin{array}{l}\text { Prates, Both e } \\
\text { Rinaldi (2019) }\end{array}$ & v. 30 \\
\hline $\begin{array}{c}\text { Revista } \\
\text { Brasileira de } \\
\text { Educação } \\
\text { Física e } \\
\text { Esporte } \\
\end{array}$ & $\begin{array}{c}\text { Gymnastics in higher education: reflections on } \\
\text { assessment }\end{array}$ & $\begin{array}{c}\text { Carbinatto e } \\
\text { Nunomura (2016) }\end{array}$ & v. 30 \\
\hline \multirow{3}{*}{ Motriz } & $\begin{array}{l}\text { Conceitos de didática: depoimentos de docentes } \\
\text { universitários da área de Educação Física }\end{array}$ & $\begin{array}{l}\text { Borges, Hunger e } \\
\text { Souza Neto } \\
(2009)\end{array}$ & $\begin{array}{l}\text { v. } 15 \text {, } \\
\text { n.2 }\end{array}$ \\
\hline & $\begin{array}{l}\text { Educação Física, esporte e cultura no Ensino } \\
\text { Superior: íntimas relações com o Brasil e a atualidade }\end{array}$ & $\begin{array}{l}\text { Silva e Zomboni } \\
(2010)\end{array}$ & $\begin{array}{l}\text { v. } 16, \\
\text { n. } 4\end{array}$ \\
\hline & $\begin{array}{l}\text { Grupo de estudo e a formação do professor de } \\
\text { Educação Física do Ensino Superior: importantes } \\
\text { contribuições para construção da identidade docente }\end{array}$ & $\begin{array}{l}\text { Batista e Moreira } \\
\text { (2015) }\end{array}$ & $\begin{array}{l}\text { n. 2, } \\
\text { Supl. } \\
\text { II, p. } \\
\text { S240- } \\
\text { S386 }\end{array}$ \\
\hline
\end{tabular}

Fonte: Elaborado pelas autoras

${ }^{2}$ Nessa edição a revista Motriz publicou os Anais dos resumos expandidos do IX Congresso Internacional de Educação Física e Motricidade Humana e XV Simpósio Paulista de Educação Física (IX CIEFMH e XV SPEF). 


\section{Mapeamento na Biblioteca Digital de Teses e Dissertações (BDTD)}

Com uma busca a partir da temática Pedagogia universitária e formação de docentes de Cursos de Educação Física, bem como considerando os descritores eleitos para as buscas, foram encontradas setenta e quatro (74) publicações, considerando os dez (10) anos de busca, entre 2009 e 2019. Dentre essas publicações visitadas, apenas sete (7) trabalhos atenderam o objetivo da busca: cinco (5) eram

Dissertações e dois (2) eram Teses, conforme evidenciado no Quadro 2, a seguir.

Quadro 2 -Publicações científicas em Teses e Dissertações.

\begin{tabular}{|c|c|c|c|}
\hline Título & Ano & Autor/orientador & $\begin{array}{l}\text { Tese/ Dissertação/ } \\
\text { Programa/ } \\
\text { Instituição }\end{array}$ \\
\hline $\begin{array}{l}\text { Sentidos da docência universitária } \\
\text { para professores das disciplinas } \\
\text { técnico esportivas da UNEB }\end{array}$ & 2011 & $\begin{array}{l}\text { Angelo Maurício de Amorim } \\
\text { Orientador: Prof. Dr. } \\
\text { Augusto César Rios Leiro }\end{array}$ & $\begin{array}{c}\text { Dissertação/ } \\
\text { Programa de Pós-Graduação em } \\
\text { Educação, Universidade Federal da } \\
\text { Bahia }\end{array}$ \\
\hline $\begin{array}{l}\text { Socialização profissional de } \\
\text { professores de Educação Física do } \\
\text { Ensino Superior }\end{array}$ & 2013 & $\begin{array}{c}\text { Andréia Fernanda Moletta } \\
\text { Orientador: Prof. Dr. Juarez } \\
\text { Vieira do Nascimento } \\
\text { Coorientadora: Prof }{ }^{\mathrm{a}} \text {. Dra } \\
\text { Gelcemar Oliveira Farias }\end{array}$ & $\begin{array}{c}\text { Dissertação/ } \\
\text { Programa de Pós-Graduação em } \\
\text { Educação Física da Universidade } \\
\text { Federal de Santa Catarina }\end{array}$ \\
\hline $\begin{array}{l}\text { A constituição da docência no } \\
\text { curso de formação em Educação } \\
\text { Física: os modos de ser, saber e } \\
\text { poder ser professor }\end{array}$ & 2015 & $\begin{array}{l}\text { Adrielle Lopes de Souza } \\
\text { Orientadora: Prof }{ }^{\mathrm{a}} \text {. Dr }{ }^{\mathrm{a}} \text {. } \\
\text { Zenólia Christina Campos } \\
\text { Figueiredo }\end{array}$ & $\begin{array}{c}\text { Dissertação/ } \\
\text { Programa de Pós-Graduação em } \\
\text { Educação Física do Centro de } \\
\text { Educação Física e } \\
\text { Desporto da Universidade Federal } \\
\text { do Espírito Santo } \\
\end{array}$ \\
\hline $\begin{array}{c}\text { Docência Universitária: os saberes } \\
\text { docentes na trajetória profissional } \\
\text { do Curso de Licenciatura em } \\
\text { Educação Física da Universidade } \\
\text { Regional do Cariri } \\
\end{array}$ & 2015 & $\begin{array}{l}\text { Amanda Raquel Rodrigues } \\
\text { Pessoa } \\
\text { Orientadora: Prof }{ }^{\mathrm{a}} \text {. Dr }{ }^{\mathrm{a}} \text {. } \\
\text { Bernadete de Souza Porto }\end{array}$ & $\begin{array}{c}\text { Dissertação/ } \\
\text { Programa de Pós-Graduação em } \\
\text { Educação Brasileira da } \\
\text { Faculdade de Educação da } \\
\text { Universidade Federal do Ceará }\end{array}$ \\
\hline $\begin{array}{c}\text { Docência no processo de inclusão } \\
\text { do estudante com deficiência em } \\
\text { cursos de Educação Física: análise } \\
\text { do contexto universitário brasileiro } \\
\text { e português }\end{array}$ & 2016 & $\begin{array}{c}\text { Soraya Dayanna Guimarães } \\
\text { Santos } \\
\text { Orientadora: Prof }{ }^{a} \text {. Dr }{ }^{\mathrm{a}} \text {. } \\
\text { Neiza de Lourdes F. Fumes } \\
\text { Coorientador: Prof. Dr. José } \\
\text { Pedro Ferreira }\end{array}$ & $\begin{array}{c}\text { Tese/ } \\
\text { Programa de Pós-Graduação em } \\
\text { Educação da Universidade Federal } \\
\text { de Alagoas }\end{array}$ \\
\hline $\begin{array}{c}\text { Docência Universitária: } \\
\text { concepções pedagógicas de } \\
\text { bacharéis em Educação Física } \\
\text { docentes em Instituiçôes de Ensino } \\
\text { Superior do sul de Santa Catarina }\end{array}$ & 2017 & $\begin{array}{c}\text { Joni Luiz Trichês dos Santos } \\
\text { Orientador: Prof. Dr. Gildo } \\
\text { Volpato }\end{array}$ & $\begin{array}{c}\text { Dissertação/ } \\
\text { Programa de Pós-Graduação em } \\
\text { Educação da Universidade do } \\
\text { Extremo Sul Catarinense (UNESC) }\end{array}$ \\
\hline $\begin{array}{l}\text { A nova classe trabalhadora vai ao } \\
\text { Ensino Superior: um estudo das } \\
\text { práticas didático-pedagógicas em } \\
\text { licenciaturas de Educação Física do } \\
\text { setor privado no Espírito Santo }\end{array}$ & 2019 & $\begin{array}{c}\text { Alessandra Galve Gerez } \\
\text { Orientador: Prof. Dr. Valter } \\
\text { Bracht }\end{array}$ & $\begin{array}{c}\text { Tese/ } \\
\text { Programa de Pós-Graduação em } \\
\text { Educação Física do Centro de } \\
\text { Educação Física e Desportos da } \\
\text { Universidade Federal do Espírito } \\
\text { Santo } \\
\end{array}$ \\
\hline
\end{tabular}

Fonte: Elaborado pelas autoras 


\section{0 que indicam o total de produções científicas consideradas neste estudo?}

Com base no estudo realizado, no que tange às produções em periódicos, teses e dissertações, constatamos que existe pouquíssima produção científica sobre a temática pesquisada. É um dado que, no escopo dos trabalhos pesquisados e entre os que tratam de estado da arte, notadamente sinalizam que a discussão quanto à pedagogia universitária e à docência dos formadores de professores de Educação Física são temas incipientes e periféricos na produção científica da área. Nesta seção, realizamos uma interlocução com os trabalhos selecionados e tecemos os temas recorrentes, assim como as constatações que marcam as análises e que vão ao encontro de nossa temática.

Diante dessa realidade, observamos que, na condição de professoras e intelectuais da docência, conforme constatamos a partir dos estudos de Rezer (2010) e, mais especificamente, de Rezer et al. (2012, p. 903), é preciso dialogar

[...] com as demandas profissionais que nossa intervenção requer. Isso solicita uma ampliação da capacidade investigativa do próprio campo a este respeito. Tal esforço pode contribuir com o alargamento da percepção de que o campo da EF e, por consequência, o trabalho docente na Educação Superior neste âmbito, permite ainda muitas possibilidades em seus "espaços livres", pois ainda estão em aberto, mesmo em meio a tensões e contradições, janelas formidáveis no cotidiano do trabalho docente na formação inicial em EF.

O trabalho docente é uma temática recorrente nas publicações analisadas, a partir dos objetivos que consideram a necessidade de se refletir acerca das demandas desse trabalho na Educação Superior, tomando como referência o campo da Educação Física e a formação de professores nessa especificidade. Também Broch et al., (2019) sinalizam em seus estudos acerca do trabalho docente:

[...] pesquisas identificadas demonstraram preocupação com aspectos que perpassam a qualificação profissional, especialmente o engajamento dos docentes com as atividades de ensino, pesquisa e extensão, muitas vezes desempenhadas de forma fragmentada, em decorrência das especificidades das IES pública e privada. Há, também, embates vivenciados por docentes, sobretudo de IES privada, quanto às limitações de acesso e incentivo à formação continuada (BROCH et al.,2019, p. 5).

Sobre esse tema, Gerez e Bracht (2019) analisam a questão da sobrecarga de trabalho docente com as disciplinas dos cursos e identificam táticas docentes para se adaptarem e resistirem ao intenso trabalho.

Importa trazermos à discussão o estudo de Pires et al. (2018, p. 396), pois essa investigação teve como objetivo conhecer os "aspectos de formação e atuação profissional de docentes universitários de Educação Física em início de carreira”. Para Pires et al. são as experiências durante a formação e no decurso da carreira docente "que estão presentes na atuação profissional” (p.404).

A construção da identidade docente é um tema que aparece nas publicações científicas analisadas. Batista e Moreira (2015) afirmam sobre a importância das trocas de experiências, tais como: a 
participação em grupos de estudo, a reflexão e a reorganização das práticas pedagógicas para a construção da identidade docente. Vale sublinhar o que dizem Vieira e Neira (2016, p. 793), pois destacam que

[...] as identidades solitárias só esvanecerão em conjunturas do Ensino Superior que facilitem a comunicação docente com seus pares e com a comunidade acadêmica, proporcionando instrumentos de ensino e pesquisa que possibilitem o enfrentamento dos desafios contemporâneos em tempos neoliberais.

Contudo, nesse contexto, há presença marcante de identidades docentes acríticas e solitárias com origem em trajetórias de vida e subjetivações constituídas face às relações de poder e aos processos históricos e sociais que mercantilizam a educação e que induzem à instauração de práticas alienantes nas instituições de Ensino Superior. Quando consideradas as discussões quanto aos componentes disciplinares, pedagógicos e práticos durante a formação inicial de professores, identifica-se que "os professores formadores parecem não se dar conta dessas práticas de significação produzidas pela cultura universitária. $\mathrm{O}$ resultado parece ser a restrição do horizonte de intervenções desses sujeitos no ambiente escolar" (GARIGLIO, 2010, p. 25).

No que tange à formação inicial, na especificidade dos estágios, os estudos de Biscosini, Flores e Oliveira (2016) evocam acerca do acompanhamento e orientação, como um processo formativo que é corresponsivo entre estagiários, professores coordenadores e supervisores. Os autores consideram relevante que os docentes envolvidos na dinâmica formativa, portanto os agentes formadores, sintam-se “parte da formação do futuro professor, na tentativa de realmente efetivar a interação entre universidade e escola, para assim, talvez, amenizar as lacunas na formação inicial de professores" (BISCOSINI; FLORES; OLIVEIRA, 2016, p. 11).

As exigências institucionais, o tipo de formação, a fraca fundamentação e a dicotomia teoria e prática afastam o discurso ideal do real, principalmente quando associado ao produtivismo. Nesse sentido, Silva, Andrade e Zanelli (2010, p. 151) sublinham que a docência universitária está relacionada à competitividade e ao "individualismo acadêmicos que afetam o status docente, o ambiente acadêmico, os objetivos institucionais e a legitimidade da universidade".

Identificamos que dentre os textos selecionados, Garcia e Pereira (2019, p. 14) mencionam acerca da "desigualdade promovida pelo sistema educacional tradicional", a qual se fez presente entre professores e estudantes, quando aqueles que sabem mais são destacados nas situações de jogo. Os trabalhos analisados no escopo das Teses e Dissertações, mais pontualmente, expressam reflexão e questionamentos acerca das concepções pedagógicas (SANTOS, 2017), das vivências e sentidos da docência na Educação Superior (AMORIM, 2011) e, desse modo, consideram como temáticas de análise: os saberes docentes, (PESSOA, 2015); a socialização profissional, (MOLETTA, 2013);o processo de 
inclusão, (SANTOS, 2016) e as práticas didático-pedagógicas no campo da Educação Física (GEREZ, 2019).

O conceito sobre didática foi um objeto de estudo que encontramos nos textos. Borges, Hunger e Souza Neto (2009, p.233) que, ao entrevistarem docentes universitários sobre o que entendem por didática, constataram que esses profissionais a conceituam, unanimemente, como a "metodologia, as técnicas de ensino e os procedimentos de como ensinar algo a alguém”. Os autores ainda sublinham que as demandas relacionadas à docência na universidade estão relacionadas ao necessário reconhecimento acerca do papel que a didática tem. Borges, Hunger e Souza Neto (2009, p.234) concluem que a didática “é relevante como parte integrante da formação para o magistério superior uma vez que é mediadora da relação professor-aluno, condutora da informação e carreadora de frutos para a sociedade que se constrói a cada dia".

Os contextos emergentes marcam presença nas investigações mapeadas. De acordo com Bolzan (2016), os contextos emergentes correspondem às transformações evidenciadas nas instituições de ensino, por meio de ações políticas, sociais, culturais e econômicas, provocando reflexão e novas formas de ser e estar no mundo da vida. Esses contextos implicam na reorganização do trabalho do professor, colocandoo diante do desafio de arquitetar e solidificar novos processos de ensinar e aprender. Nesse viés, o estudo realizado por Marcon, Graça e Nascimento (2012) indica a relevância da participação dos professores formadores nas intermediações, nas ações e operações diante dos contextos emergentes, tal como no que tange ao projeto político-pedagógico do curso.

Os movimentos de autoformação marcam presença nos textos estudados neste mapeamento. Os professores, mediante a experiência de uma prática reflexiva com base na escrita de diários, assumem-se como protagonistas na análise da própria prática e da produção de saberes e, assim, edificam a compreensão da formação de si. Muñhoz, Rossi e Riveros (2017), ao estudarem a atividade reflexiva por meio da escrita de diários, reconhecem essa prática como constitutiva do profissional docente.

Assim, as aprendizagens docentes despontaram nas publicações analisadas, a partir da percepção da atuação de si próprios durante as vivências, assumindo um caráter formativo dessas concepções. Nessa mesma perspectiva, Carbinatto e Nunomura (2016), ao discorrerem sobre avaliação, indicam que esta recebeu um caráter distinto de antigamente, tornando-se mais reflexiva e analítica. Nesse sentido, Alves, Carvalho e Dias (2011, p. 255) identificam que os relatos "são exercícios que trazem as marcas da transgressão, dos pontos de fuga, de invenção e ousadia daquele que se lança ao exercício profissional".

Vale sublinhar que Krüger e Krug (2009, p. 63) revelam que as concepções dos professores foram sendo reconstruídas no decurso da carreira e com "sua inserção no contexto universitário e que, com o 
passar do tempo, estão ganhando vez e voz no eco das necessidades formativas”. Nesse viés, Prates, Both e Rinaldi (2019) trazem ainda a discussão acerca da paixão por ensinar e imbricam esse sentimento à experiência docente e ao maior tempo de docência.

O processo formativo de docentes formadores de professores de Educação Física está em diálogo com temáticas distintas, a exemplo das reflexões acerca dos pressupostos que orientam para uma abordagem crítica e cultural do esporte no processo da formação de professores. Nesse sentido, Silva e Zombini (2010) arquitetam a reflexão com base na prática esportiva como meio de formação da cultura e assinalam que é circular a relação existente entre cultura e esporte, pois, para esses autores, assim como o esporte é cultura, também a cultura determina o que vem a ser o esporte.

Os pesquisadores no campo da pedagogia universitária, a partir dos trabalhos que estudamos neste texto, no contexto da docência no Ensino Superior e na especificidade da Educação Física, pontuam que há necessidade de maior empreendimento nas experiências formativas do docente formador.

Com essas publicações, não nos foi possível identificar a aprendizagem como paradigma central nas práticas pedagógicas dos formadores de professores de Educação Física. Desse modo, essa investigação engendra pesquisas futuras para conhecer as trajetórias formativas docentes, em termos de estudos e atos pedagógicos na perspectiva da desconstrução e da reconstrução do conhecimento de ser professor, de saber ser e poder ser professor (SOUZA, 2015), no contexto da Educação Física.

\section{Considerações finais}

O que apreendemos do mapeamento realizado indica-nos a necessidade de continuidade e incremento em pesquisas sobre a docência universitária no campo da Educação Física e, fundamentalmente, acerca da aprendizagem docente dos formadores. Não podemos deixar de mencionar uma possível tendência de aumento nos estudos, se considerarmos os últimos cinco anos, quando observamos as publicações de periódicos na área.

Vale sublinhar que identificamos uma ausência em relação aos paradigmas de aprendizagem que possam orientar ações dos professores formadores de Educação Física em aulas. No entanto, no conjunto das produções analisadas há elementos que se fazem presentes, tais como: os saberes e/ou conhecimentos subjacentes à docência universitária, os sentidos a ela atribuídos e os processos de sua construção.

Ao considerarmos esse cenário estudado, é possível compreender que as pesquisas na área da Educação Física, abordando a pedagogia universitária e a formação de formadores de professores da 
Educação Física, são ainda incipientes, embora identifiquemos movimentos que engendram a autoformação de professores do Ensino Superior, os quais nascem de atividades e processos que visam a reflexão sobre e na própria docência. Com base no que observamos, ao escreverem diários, os docentes universitários reconhecem a si próprios e se colocam em movimento de aprendizagem da docência, ainda que não se desloquem para a aprendizagem do outro que está em formação inicial. O tempo de docência é constitutivo e importante, pois é no decurso das atividades docentes que surge a paixão por ensinar e é quando as concepções sobre docência universitária são construídas.

Nessa perspectiva, a socialização é possibilidade formativa e com ela os saberes docentes, as práticas didático-pedagógicas, as reflexões acerca dos contextos emergentes, a exemplo da inclusão; todas essas ponderações marcam presença nas investigações analisadas. Entretanto, existe também a presença de práticas alienantes no Ensino Superior, as quais são constatadas em discussões que consideram as identidades docentes como solitárias e até acríticas.

No caminho das análises realizadas, a didática é o objeto de estudo e seu conceito revela-se como: metodologia, técnica e procedimento de ensino. Nesse contexto, o papel da didática revela-se como um importante intercessor na formação, especialmente porque a didática é mediadora da relação entre professor e aluno. Das publicações selecionadas com o mapeamento, a que nos propomos, e das análises que engendraram desses textos, fica a necessidade de explicarmos que não se esgotam as discussões nesse estudo e que essas reflexões não cabem nos limites do texto que enunciamos.

\section{Referências}

ALVES, F. S.; CARVALHO, Y. M. de.; DIAS, D. A "escrita de si" na formação em educação física. Movimento, Porto Alegre, v. 17, n. 02, p. 239-258, abr./jun. 2011.

AMORIM, A. M. de. Sentidos da docência universitária para professores das disciplinas técnicoesportivas da UNEB. 2011. 209 f. Dissertação (Mestrado em Educação), Universidade Federal da Bahia, Salvador, 2011.

BAKHTIN, M. Para uma filosofia do ato responsável. Tradução de Valdemir Miotello e Carlos Alberto Faraco. São Paulo: Pedro \& João Editores, 2010.

BATISTA, D.; MOREIRA, E. C. Grupo de estudo e a formação do professor de educação física do ensino superior: importantes contribuições para construção da identidade docente. Motriz, Rio Claro,v. 21, n. 2, Suplemento II, p. S240-S386, abr./jun. 2015.

BDTD. Biblioteca de Teses e Dissertações. Disponível em: < $\underline{\text { https://sistema.bibliotecas- }}$ bdigital.fgv.br/bases/biblioteca-digital-de-teses-e-dissertacoes-bdtd-ibict> Acesso em: 19 nov. 2019. 
BISCOSINI, C. R.; FLORES, P. P.; OLIVEIRA, A. A. B. de. Formação inicial para a docência: o estágio curricular supervisionado na visão de seus coordenadores. Journal of Physical Education, Maringá, v. 27, e2702, 2016.

BOLZAN, D. P. V.Docência e processos formativos: estudantes e professores em contextos emergentes. Projeto de Pesquisa. Universal - MCTI/CNPq nº 01/2016.UFSM, 2016.

BORGES, C.; HUNGER, D.; SOUZA NETO, S. de. Conceitos de didática: depoimentos de docentes universitários da área de Educação Física. Motriz, Rio Claro, v. 15, n. 2, p.228-235, abr./jun. 2009.

BROCH, C. et al. O trabalho docente no ensino superior em educação física sob a ótica dos pesquisadores brasileiros. Pensar a Prática, Goiânia, v. 22, n. 5, p. 45-96, 2019.

CARBINATTO, M. V.; NUNOMURA, M. Gymnastics in higher education: reflections on assessment. Revista Brasileira de Educação Física e Esporte, São Paulo, v. 30, n. 1, p.171-181, jan./mar. 2016.

CUNHA, M. I; BROILO, C. Pedagogia universitária e produção de conhecimento. Porto Alegre: EDIPUCRS, 2008.

CUNHA, M. I. da. Ensino como mediação da formação do professor universitário In: MOROSINI, M. C. (Org.). Professor do ensino superior: identidade, docência e formação. Brasília: INEP, 2000. p. 45-51.

FIGUEIREDO, Z. C. C. et al. Educação Física, ser professor e profissão docente em questão. Revista Pensar a Prática. V. 11, n. 2, 2008.

FIGUEIREDO, Z. C. C. Formação docente em Educação Física: experiências sociais e relação com o saber. Movimento. Porto Alegre, v. 10, n. 1, p. 89-111, 2004.

GARCIA, R.M.; PEREIRA, E. G. B. Um ensaio sobre o método emancipatório de ensino na Educação Física. Motrivivência, Florianópolis, v. 31, n. 57, p. 01-17, jan./mar. 2019.

GARIGLIO, J. A. O papel da formação inicial no processo de constituição da identidade profissional de professores de educação física. Revista Brasileira de Ciências do Esporte, Florianópolis, v. 32, n. 2-4, p. 11-28, dez. 2010.

GEREZ, A. G.; BRACHT, V. As faces da precariedade do trabalho docente e as estratégias de ação de professores de educação física atuantes no ensino superior privado mercantil. Motrivivência, Florianópolis, v. 31, n. 60, p. 01-23, out./dez. 2019.

GEREZ, A. G. A nova classe trabalhadora vai ao ensino superior: um estudo das práticas didáticopedagógicas em licenciaturas de educação física do setor privado no Espírito Santo. 2019. 314 f. Tese (Doutorado em Educação Física), Universidade Federal do Espírito Santo, Vitória, 2019.

ISAIA, S. M. A. Enciclopédia de Pedagogia Universitária: glossário. Editora chefe: Marília Costa Morosini. Brasília: Instituto Nacional de Estudos e Pesquisas Educacionais Anísio Teixeira/RIES, 2006. 2 $\mathrm{v}$.

ISAIA, S. M. A.; BOLZAN, D. P. V. Diálogo interdiscursivo sobre formação docente a partir da rede de pesquisadores - RIES. LASA International Congress, 2007. 
ISAIA, S. M. de A.; BOLZAN, D. P. V.; MACIEL, A. M. da R. (Orgs.). Pedagogia universitária: tecendo redes sobre a educação superior. Santa Maria, Editora da UFSM, 2009.

KRÜGER, L. G.; KRUG, H. N. Licenciatura em educação física: concepções a partir da vivência experienciada dos professores do ensino superior em seu percurso formativo. Movimento, Porto Alegre, v. 15, n. 01, p. 51-70, jan./mar. 2009.

MARCON, D.; GRAÇA, A. B. dos.; NASCIMENTO, J. V. do. Práticas pedagógicas como cenário para a construção do conhecimento pedagógico do conteúdo dos futuros professores de educação física. Revista de Educação Física/UEM, Maringá, v. 23, n. 2, p. 295-306, 2. trim. 2012.

MARTINS. A. C. Processo formativo de professores de língua inglesa: Ser formador e Ser professor sem álibis. Jundiaí - SP: Paco Editorial, 2018. 1. ed.

MOLETTA, A. F. Socialização profissional de professores de educação física do ensino superior. 2013. 169 f. Dissertação (Mestrado em Educação Física), Universidade Federal de Santa Catarina, Florianópolis, 2013.

MOROSINI, M. C. Enciclopédia de Pedagogia universitária. Glossário. INEP/RIES, 2006. 2 v.

MUÑHOZ, J. A. J.; ROSSI, F.; RIVEROS, C. G. A prática reflexiva como possibilidade de construção de saberes: contribuições para a formação docente na educação física. Movimento, Porto Alegre, v. 23, n. 2, p. 587-600, abr./jun. de 2017.

NÓVOA. A. Os professores e sua formação. Lisboa: Publicações Dom Quixote, 1995.

PÉREZ-GÓMES, A. O pensamento prático do professor: a formação do professor como profissional reflexivo. In: NÓVOA, A. (Org.). Os professores e sua formação. Lisboa: Dom Quixote, 1992. p. 93 114.

PESSOA, A. R. R. Docência universitária: os saberes docentes na trajetória profissional do curso de licenciatura em educação física da Universidade Regional do Cariri. 2015. 195 f. Dissertação (Mestrado em Educação), Universidade Federal do Ceará, Fortaleza, 2015.

PIRES, A. F. et al. A docência universitária em educação física: da formação à atuação profissional. Pensar a Prática, Goiânia, v. 21, n. 2, abr./jun. 2018.

PRATES, M. E. F.; BOTH, J.; RINALD, I. P. B. Os professores de educação física e a paixão pela atividade docente no ensino superior. Journal of Physical Education, Maringá, v. 30, e3015, 2019.

REZER, R. et al. Trabalho docente na educação superior: reflexões epistemológicas no campo da educação física. Revista Brasileira de Ciências do Esporte, Florianópolis, v. 34, n. 4, p. 891-908, out./dez. 2012.

REZER, R. Reflexiones didáctico-pedagógicas acerca de la enseñanza del deporte en el proceso de formación de profesores de educación física. Movimento, Porto Alegre, v. 16, n. 01, p. 271-292, ene./mar. 2010. 
SANTOS, J. L. T dos. Docência universitária: concepções pedagógicas de bacharéis em educação física docentes em IES do sul de Santa Catariana. 2017. 131 f. Dissertação (Mestrado em Educação), Universidade do Extremo Sul Catarinense, Criciúma, 2017.

SANTOS, S. D. G. Docência no processo de inclusão do estudante com deficiência em cursos de educação física: análise do contexto universitário brasileiro e português. 2016. 288 f. Tese (Doutorado em Educação), Universidade Federal de Alagoas, Maceió, 2016.

SCHÖN, D. Formar professores como profissionais reflexivos. In: NÓVOA, A. (Org.). Os professores e sua formação. Lisboa: Publicações Dom Quixote: 1995. p. 77-91.

SILVA, A. C. e.; ZOMBONI, M. Z. Educação física, esporte e cultura no ensino superior: íntimas relações com o Brasil e a atualidade. Motriz, Rio Claro, v. 16, n. 4, p. 1045-1051, out./dez. 2010.

SILVA, R. da. S.; ANDRADE, A.; ZANELLI, J. C. O discurso real e o discurso ideal de professores de educação física do ensino superior sobre docência. Movimento, Porto Alegre, v. 16, n. 03, p. 133-154, jul./set. 2010.

SOUZA, A. L de. A constituição da docência no curso de formação em educação física: os modos de ser, saber e poder ser professor. 2015. 87 f. Dissertação (Mestrado em Educação Física), Universidade Federal do Espírito Santo, Vitória, 2015.

TEIXEIRA, F. T. et al. Formação de professores universitários na pós-graduação stricto sensu em Educação Física no Brasil: uma revisão sistemática. Motrivivência, Florianópolis, v. 31, n. 59, p. 01-21, jul./set. 2019.

VIEIRA, R. A. G.; NEIRA, M. G. Identidade docente no ensino superior de educação física: aspectos epistemológicos e substantivos da mercantilização educacional. Movimento, Porto Alegre, v. 22, n. 3, 783-794, jul./set. de 2016.

ZEICHNER, K. M. A formação reflexiva de professores: ideias e práticas. Lisboa: Educa, 1993.

\section{Como citar este artigo}

MARTinS, A. C.; ClATES, D. M.; ElESBÃO, H.; CAMARGO, M. C. S. Pedagogia universitária e formadores de professores de Educação Física: o que expressam as produções científicas? Revista Kinesis, Santa Maria, v. 38, p.01-16, 2020.

* Este texto integra o projeto de pesquisa da professora Adriana Cláudia Martins, bolsista PNPD/Capes do Programa de Pós-graduação em Educação Física, intitulado "Formadores de Professores de Educação Física: o tom volitivo da Pedagogia Universitária", aprovado pelo Comitê de Ética sob registro CAAE 24768719.0.0000.5346 e teve apoio financeiro da Coordenação de Aperfeiçoamento de Pessoal de Nível Superior - Brasil (CAPES) - Código de Financiamento 001.

* Este trabalho teve apoio financeiro da Coordenação de Aperfeiçoamento de Pessoal de Nível Superior Brasil (CAPES) - Código de Financiamento 001, por parte da bolsista Heloisa Elesbão. 